\author{
LESZEK ŻYREK \\ WOJCIECH ZASADNI \\ JAN LUBRYKA \\ DAWID JENDROSKA
}

\title{
Mobile lighting of passenger and material monorails stations
}

\begin{abstract}
In this article, the authors present the Becker-Warkop company innovative technology development of mobile lighting for passenger and material stations as well as routes during the passage of a suspended monorail. As part of the paper, a technical solution was presented along with its configuration options. The paper also includes standard requirements along with a description of the experiences and good practices obtained during the implementation of this technology.
\end{abstract}

Key words: mobile lighting, suspended monorail, experience, practice

\section{INTRODUCTION}

The innovative solution proposed by Becker-Warkop is a direct response to the specific needs of our customers in the area of lighting for mobile and material stations. The mobile lighting of the station gives the possibility of eliminating standalone lighting by using lamps mounted on passenger cabins and transport sets of suspended monorail machines [1]. The use of this lighting technology and the possibility of using it not only at the stations but also during the length of the entire driven routes significantly increases the safety as well as the economic and energy efficiency of the mine. This solution is protected by a patent. Below, we present its details and best practices.

\section{SOLUTION DESCRIPTION}

Standard standalone lighting of material and personal stations requires constant rebuilding as work progresses. An additional aspect in favor of mobile lighting is the fact that, after the installation of stationary lighting, it works all of the time (not only when it is actually needed), which is the reason for generating increased costs for energy and the consumption of lighting lamps.

The use of the mobile lighting of suspended monorails with their own drives eliminates the use of electrical devices and power lines from mining routes at risk of explosion, thus increasing the level of anti-explosive safety. To obtain the functionality of mobile lighting for a suspended monorail, the following devices are needed:

- UZOD-02 additional lighting supply system,

- type ŚWIT-14 / MOD [2] lamps (lighting for passenger stations) and type OLR-1-18 / MOD [3] (lighting for material stations) lamps,

- KS-01/1/5 control box in cabins,

- flameproof connectors of PC220 series.

Thanks to these devices, it is possible to implement changes to the power supply system of the machine and add an optional supply of UZOD-02 lighting, thanks to which we obtain the effect presented in Figure 1.

The functionality that is obtained through the use of this solution is to illuminate passenger and/or material stations as well as selected places on the route of the monorail through the mine. Figure 2 shows the placement of an additional UZOD-2 system on the motor part of a suspended monorail. 

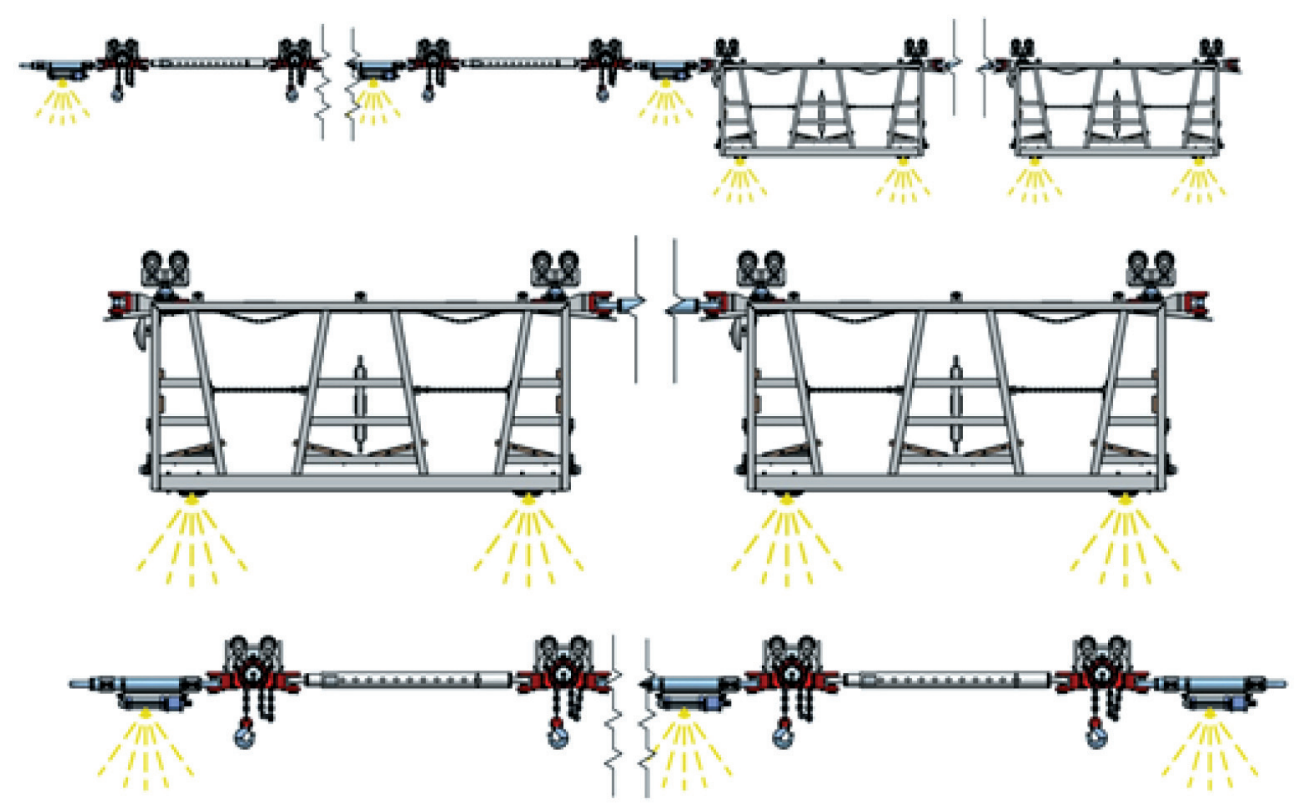

Fig. 1. Example of lighting installation on passenger cabins and transport sets [4]

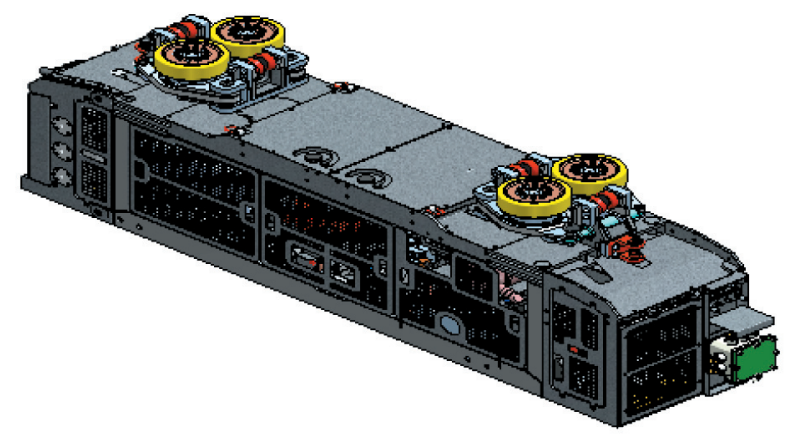

Fig. 2. Example of UZOD-02 power supply system installation on motor part [1]

The remaining elements of the mobile lighting can be installed in cabins suitable for this purpose, having the appropriate approvals of the President of the State Mining Authority; e.g., UIK KO-8-A passenger cabins, UIK KOS-A sanitary cabins, or also built on dedicated adapters serving as hanging lamps on a transport set. Figure 3 presents an example of the SWIT lamps for passenger cabins. Due to their location, the lamps must be properly attached to the cabin, taking into account their dimensions. Placing lamps in passenger cabins is the result of many months of work and testing of the lighting parameters. Another important aspect are vibrations, which are largely eliminated by shock absorbers. Thanks to the applied springs, the effect of retracting the lamps in the cabin is obtained when it comes in contact with the platform, which in combination with the metal cover of the lampshade lamps (from metal rods) results in increased resistance to mechanical damage [3].
In the case of lamps used on transport sets, it is very important to place the lamp under the rod itself so that the emitted light is not limited by the transported load nor by the hydraulic and electrical lines. In addition, special brackets should be used to support the PC220 quick couplers that enable the quick reconfiguration of the sets. The additional power cord of the lamp should be guided through the designated clamps for the hydraulic and electrical lines. An exemplary solution is demonstrated in Figure 4.

The number of lighting sources is limited by the power of the alternator feeding the monorail control system, which is $240 \mathrm{~W}$ for the KP-95 and KP-148 monorails. The following values should be used for the calculations:

- two lamps of ŚWIT-14/MOD type for one personal cabin $(2 \times 10 \mathrm{~W})$,

- one OLR-1-18/MOD lamp for one pull rod of the transport set $(1 \times 10 \mathrm{~W})$. 


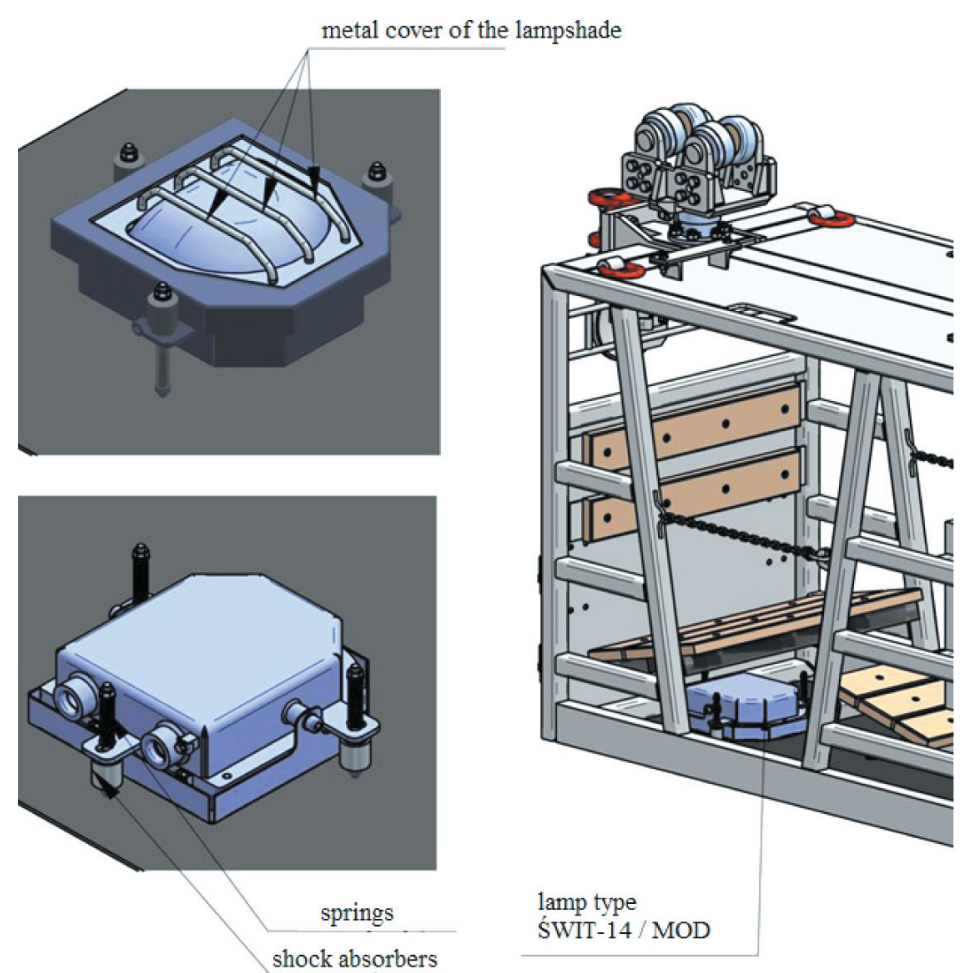

Fig. 3. Sample installation of SWIT lamps in passenger cabin

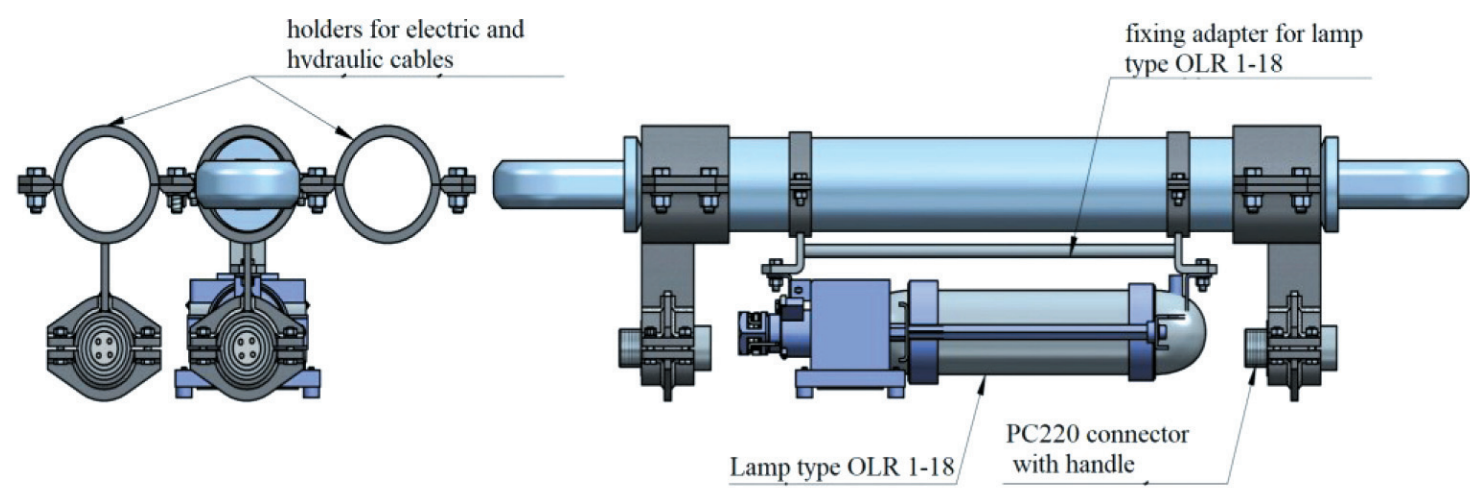

Fig. 4. Exemplary installation of OLR lamp on transport set

The UZOD-02 additional lighting supply system ensures the required performance program for switching LED lights on and off with the KS-01/1/5 control box; i.e., switching lamps intended for lighting passenger stations (ŚWIT-14/MOD lamps) or switching lamps for lighting material stations or lamps intended for simultaneously switching lamps on or off for lighting passenger and material stations. An example of the arrangement of the KS-01/1/5 cassette in the operator's cabin is shown in Figure 5.

If the insulation resistance is lower than $10 \mathrm{k} \Omega$, a warning message will be generated by the monorail control system. The device controlling the insulation condition is a standard protection of the monorail installation built into the ZUSD-01 power supply unit.
After connecting additional devices (lamps), this circuit is also controlled by this protection.

Additional level of protection built into the supply system for the UZOD-02 additional lighting is protection that controls the continuity of the grounding on its outflows. Any disturbance in the electrical system (i.e., short circuiting, opening, a too high resistance of the loop, or the incorrect termination of the earth continuity monitoring circuit or other defects) are additionally monitored by the monorail's control system, and the appropriate messages are displayed on the WLM-01 (Fig. 7) or MSPM-01 or 04 displays (Fig. 6). The termination of the earth continuity monitoring circuit is done by a male protective cover (BM-PC220) or a diode built into the lamp. 


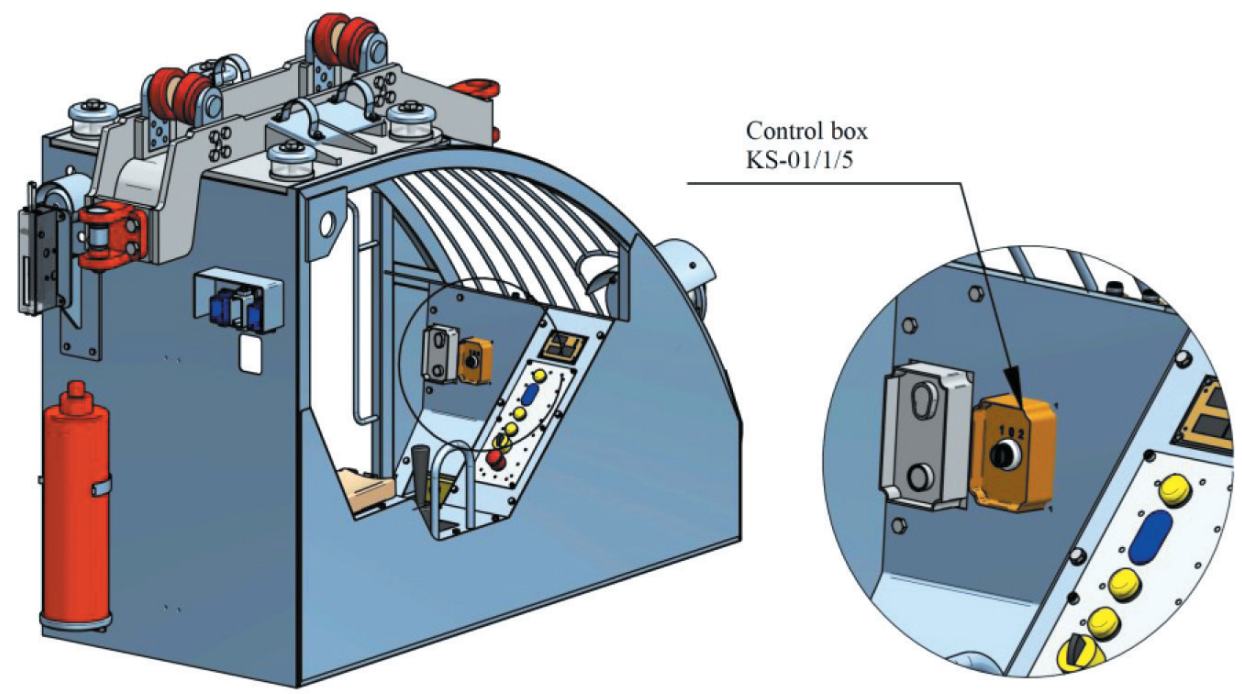

Fig. 5. Placement of KS-01/1/5 box in operator's cabin [3]

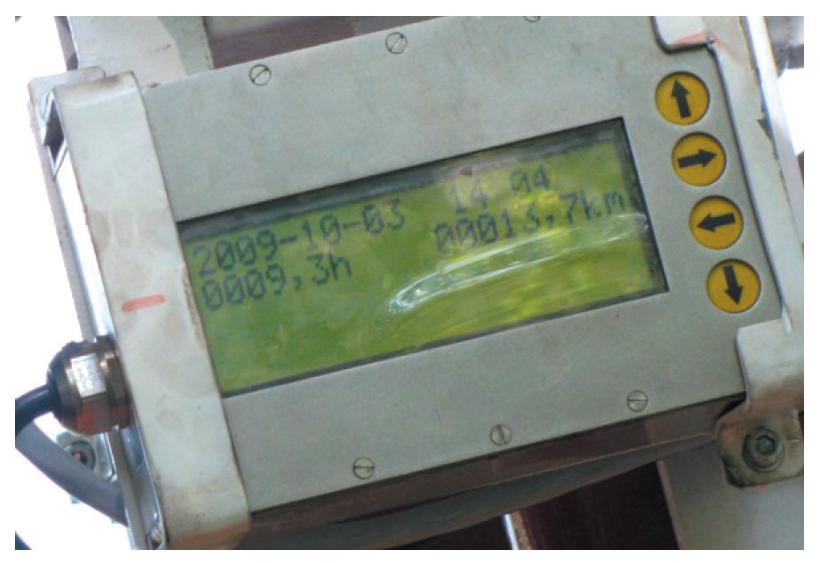

Fig. 6. Machine status monitor type MSPM-01

The sets between themselves and the motor part are connected via PC220-series quick connectors. Figure 8 shows an example configuration of a human transport monorail equipped with a PC220-series connector system.

It is allowed to make connections between cabins and transport sets using cable - cable glands to reduce costs.

Up until July 2017 (before each lighting system replacement of the lighting of passenger and material stations), it was necessary to measure the intensity of the lighting, uniformity factor, and inventory ratio by qualified personnel with appropriate qualifications.

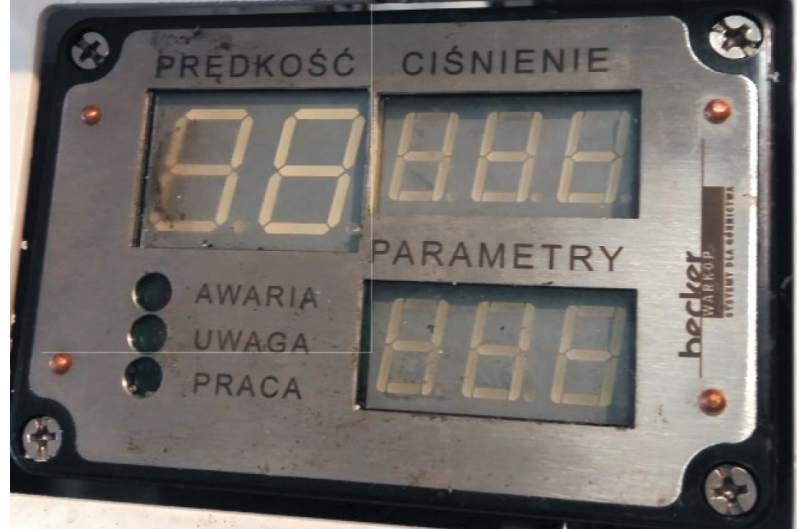

Fig. 7. Driver's display type WLM-01

During the implementation of this solution, the measurements of the personal and material stations at the JSW SA and KWK Krupiński mine were made in 2016 by OPA-ROW Sp. z o.o. (Environmental Research Laboratory) included in the reports confirmed that the lighting installation built under the passenger cabins and under the tie rods of the transport sets met the requirements of PN-G-02600 "Lighting of underground mining plant operations" [5].

The Polish standard in Point 2.4.1 explicitly defined that, in the excavation corridors, the smallest allowable average illuminance, uniformity of lighting, and inventory factor should correspond to the values in Table 1.

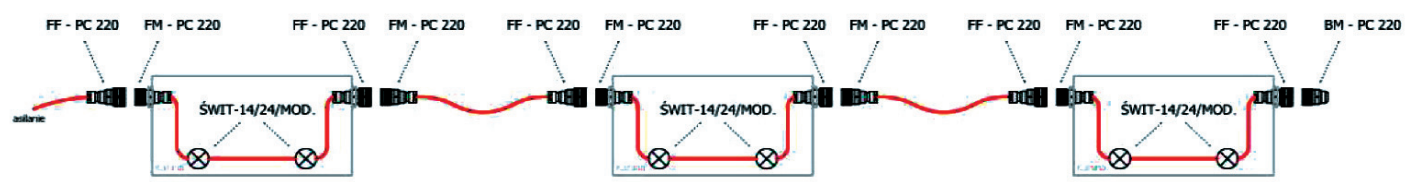

Fig. 8. Examples of electrical connection of lighting between cabins [2] 
Table 1

Required illumination according to PN-G-02600

\begin{tabular}{|c|c|c|c|c|c|}
\hline \multirow[b]{2}{*}{ No. } & \multirow[b]{2}{*}{ Illuminated area } & \multirow[b]{2}{*}{$\begin{array}{c}\text { Illuminated } \\
\text { surface }\end{array}$} & \multirow[b]{2}{*}{$\begin{array}{c}\text { Factor } \\
\text { inventory }\end{array}$} & \multicolumn{2}{|c|}{ Parameters lighting } \\
\hline & & & & $\begin{array}{c}\text { intensity } \\
\text { lighting } \\
E_{\text {Wed. }}[\mathbf{l x}]\end{array}$ & $\begin{array}{c}\text { uniformity } \\
\text { lighting } \\
\delta_{s r}=\frac{E_{\text {min }}}{E_{s r}}\end{array}$ \\
\hline 1 & 2 & 3 & 4 & 5 & 6 \\
\hline 1 & Shaft bottom & bottom & 1.5 & thirty & 0.4 \\
\hline 2 & $\begin{array}{l}\text { Shaft bottom - entrance to the cage, workstation } \\
\text { for the signaller }\end{array}$ & $\begin{array}{l}\text { bottom, heights with } \\
\text { signaling equipment }\end{array}$ & 1.5 & thirty & 0.3 \\
\hline 3 & Passenger station with rail transport & $\begin{array}{l}\text { bottom on the side of } \\
\text { the entrance to the carts }\end{array}$ & 1.5 & thirty & 0.4 \\
\hline 4 & Passenger station with tire transport & bottom & 1.5 & 20 & 0.4 \\
\hline 5 & $\begin{array}{l}\text { Platforms for getting on the conveyor and getting off } \\
\text { the conveyor }\end{array}$ & bottom & 1.5 & 20 & 0.3 \\
\hline 6 & Pier, horizontal or sloping footpath for pedestrian traffic & $\begin{array}{l}\text { bottom, transition } \\
\text { for people }\end{array}$ & 1.5 & 5 & 0.2 \\
\hline 7 & $\begin{array}{l}\text { The route of the queue and other means used for } \\
\text { transporting people (without pedestrian traffic) }\end{array}$ & bottom & 1.5 & 2 & 0.2 \\
\hline 8 & $\begin{array}{l}\text { Turnouts, forks, intersections, narrowing, intersection of } \\
\text { pedestrian crossings with the conveyor route on major roads }\end{array}$ & bottom & 1.5 & 10 & 0.3 \\
\hline 9 & Dams (on both sides) on the main transport routes & bottom & 1.5 & 10 & 0.3 \\
\hline 10 & Station material, loading, transfer & edge car, trellis & 2.0 & 10 & 0.3 \\
\hline 11 & Station borders & bottom & 2.0 & 5 & 0.2 \\
\hline 12 & $\begin{array}{l}\text { Other workplaces and places of installation of machines and } \\
\text { devices, communication means, etc. in sidewalks and trenches }\end{array}$ & $\begin{array}{l}\text { bottom or other work } \\
\text { surfaces }\end{array}$ & 1.5 & 10 & 0.3 \\
\hline
\end{tabular}

According to the latest ordinance of the Minister of Energy from November 23, 2016, regarding the detailed requirements for the operation of underground mining in Annex 4, Section 4.9. Rope transport and self-propelled transport sets are defined as:

“4.9.7. Illuminates:

1) $(\ldots)$;

2) stations during loading or unloading;

3) passenger stations when people are boarding or disembarking".

In addition, when driving a monorail, the road can be additionally illuminated (which increases the level of safety).

\section{SUMMARY}

The simple and at the same time innovative solution proposed by Becker-Warkop presented above has been developed as a solution resulting from the specific needs of our clients. It provides not only technological and economic benefits in the area of lighting for passenger and material stations but also improves the safety of the crew working near the suspended railway route at the time of a particular threat (that is, during monorail movement). This is one of the examples of cooperation between Becker-Warkop and our clients, who are our inspiration and partners.

\section{References}

[1] Annex no. 6 to the Instruction Manual of a suspended monorail type KP-95 - applicable to mobile lighting of mobile and material stations.

[2] User's manual for the ŚWIT-14 / MOD type lamp from Elektrometal S.A.

[3] User's manual for OLR-1-18 / MOD type lamps from Elektrometal S.A.

[4] Datasheet of Becker-Warkop mobile lighting.

[5] Annex no. 6 of the Service Manual of a KP-148 suspended type tractor mobile lighting station of the KP-148 railway station - applicable to mobile lighting of passenger and material stations

LESZEK ŻYREK, Eng. WOJCIECH ZASADNI, Ph.D., Eng. JAN LUBRYKA, M.Sc., Eng. DAWIDJENDYSKA, M.Sc., Eng. Becker-Warkop Sp. zo.o. ul. Przemystowa 11, 44-266 Świerklany, Poland \{l.zyrek, w.zasadni, j.lubryka, d.jendroska\} @becker-mining.com.pl 
LESZEK ŻYREK

WOJCIECH ZASADNI

JAN LUBRYKA

DAWID JENDROSKA

\title{
Mobilne oświetlenie stacji osobowych i materiałowych kolejek podwieszonych
}

\begin{abstract}
$W$ artykule przedstawiono opracowana przez firmę Becker-Warkop sp. z o.o. innowacyjna technologię mobilnego oświetlenia stacji osobowych i materiatowych oraz trasy podczas przejazdu kolejek podwieszonych z napędem wtasnym. Omówiono rozwiazanie techniczne wraz z jego możliwościami konfiguracyjnymi, a także wymagania normowe wraz z opisem doświadczeń $i$ dobrych praktyk pozyskanych podczas wdrożeń tej technologii.
\end{abstract}

Słowa kluczowe: mobilne oświetlenie, kolejki podwieszane z napędem wtasnym, doświadczenia, praktyki

\section{WSTĘP}

Innowacyjne rozwiązanie proponowane przez firmę Becker-Warkop jest bezpośrednią odpowiedzią na konkretne potrzeby naszych klientów w obszarze oświetlenia stacji osobowych i materiałowych. Mobilne oświetlenie stacji daje możliwość wyeliminowania oświetlenia stacjonarnego przez korzystanie z lamp zabudowanych na kabinach osobowych oraz zestawach transportowych maszyn podwieszanych $\mathrm{z}$ napędem własnym [1]. Zastosowanie tej technologii oświetlenia oraz możliwość jego wykorzystania nie tylko na stacjach, ale i długości całej trasy przejazdu kolejki w znaczącym stopniu podnosi bezpieczeństwo oraz efektywność ekonomiczną oraz energetyczną zakładu górniczego. Rozwiązanie to jest chronione patentem. Poniżej przedstawiamy jego szczegóły oraz najlepsze praktyki.

\section{OPIS ROZWIAZANIA}

Standardowe stacjonarne oświetlenie stacji materiałowo-osobowych wymaga ciągłego przebudowywania wraz z postępem robót. Dodatkowym aspektem przemawiającym za mobilnym oświetleniem jest fakt, że po zabudowie stacjonarnego oświetlenia pracuje ono cały czas, a nie tylko wtedy, kiedy jest faktycznie potrzebne, co jest przyczyną generowania zwiększonych kosztów zarówno za energię, jak i zużycie lamp oświetleniowych.

Stosowanie mobilnego oświetlenia kolejek podwieszonych z własnym napędem eliminuje wykorzystanie urządzeń elektrycznych i linii je zasilających ze stacjonarnych wyrobisk zagrożonych wybuchem i tym samym podnosi poziom bezpieczeństwa przeciwwybuchowego.

Do uzyskania funkcjonalności mobilnego oświetlenia dla kolejki podwieszonej wymagane są takie urządzenia, jak:

- układ zasilania oświetlenia dodatkowego typu UZOD-02,

- lampy typu ŚWIT-14/MOD [2] (oświetlenie stacji osobowych) oraz lampy typu OLR-1-18/MOD [3] (oświetlenie stacje materiałowe),

- kasety sterownicze typu KS-01/1/5 w kabinach,

- ognioszczelne złącza serii PC220.

Dzięki tym urządzeniom jest możliwe wprowadzenie zmian do układu zasilania maszyny oraz dodanie opcjonalnego zasilania oświetlenia typu UZOD-02, dzięki któremu uzyskujemy efekt przedstawiony na rysunku 1.

Funkcjonalność, jaką zyskuje się w wyniku zastosowania tego rozwiązania, polega na oświetlaniu stacji osobowych i/lub materiałowych, jak również wybranych miejsc w kopalni na trasie przejazdu ciągnika. 

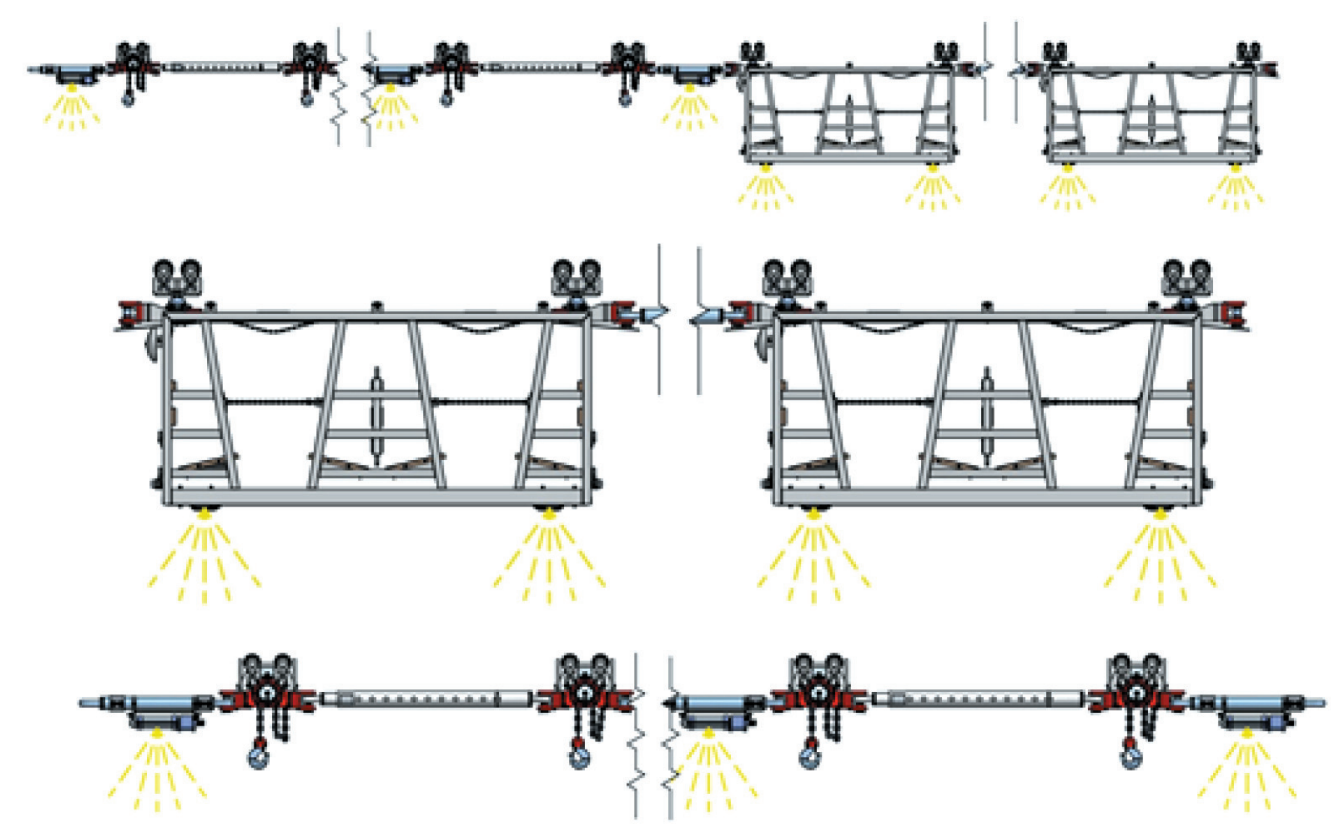

Rys. 1. Przyktadowa zabudowa oświetlenia na kabinach osobowych oraz zestawach transportowych [4]

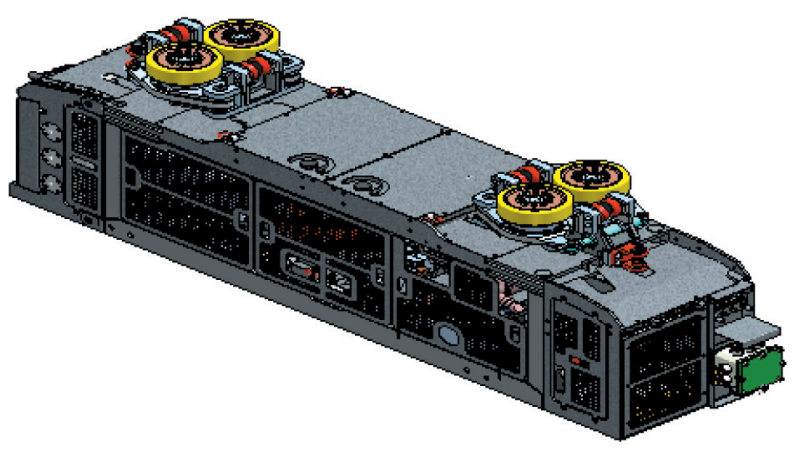

Rys. 2. Przykładowa zabudowa układu zasilania dodatkowego typu UZOD-02 na części silnikowej [1]

Na rysunku 2 zademonstrowano umieszczenie dodatkowego układu typu UZOD-2 na części silnikowej ciągnika podwieszonego.

Pozostałe elementy mobilnego oświetlenia mogą być zabudowywane w kabinach do tego przystosowanych i posiadających stosowne dopuszczenia prezesa Wyższego Urzędu Górniczego, np. w kabinach osobowych typu UiK KO-8-A, w kabinach osobowo-sanitarnych typu UiK KOS-A lub też zabudowane na specjalnych adapterach służących do zawieszenia lamp oświetlających zestaw transportowy na cięgłach łączących. Na rysunku 3 została przedstawiona przykładowa zabudowa lamp typu SWIT do kabin osobowych. Lampy z uwagi na ich miejsce zabudowy muszą być odpowiednio przymocowane do kabiny z uwzględnieniem ich gabarytów. Umieszczenie lamp w kabinach osobowych jest wynikiem wielu miesięcy prac i badań parametrów oświetlenia. Kolejnym istotnym aspektem są drgania, które są eliminowane w dużym stopniu przez amortyzatory. Dzięki zastosowanym spręży- nom uzyskuje się efekt chowania lamp w kabinie w chwili jej stykania się ze spągiem, który to w połączeniu z metalową osłoną klosza (z metalowych prętów) lamp skutkuje zwiększeniem odporności na uszkodzenia mechaniczne [3].

W przypadku lamp stosowanych na zestawach transportowych bardzo istotną kwestią jest samo umieszczenie lampy pod cięgłem tak, aby emitowane światło nie było ograniczane transportowanym ładunkiem oraz przewodami hydraulicznymi i elektrycznymi. Dodatkowo należy stosować specjalne obejmy do podtrzymania szybkozłączy typu PC220 umożliwiających szybką rekonfigurację zestawów. Dodatkowy przewód zasilający lampy powinien być prowadzony przez wyznaczone do tego zadania obejmy na przewody hydrauliczne i elektryczne. Przykładowe rozwiązanie zostało zademonstrowane na rysunku 4.

Liczba źródeł oświetlenia jest limitowana przez moc alternatora zasilającego układ sterowania ciągnika, która dla ciągników KP-95 i KP-148 wynosi 240 W. 


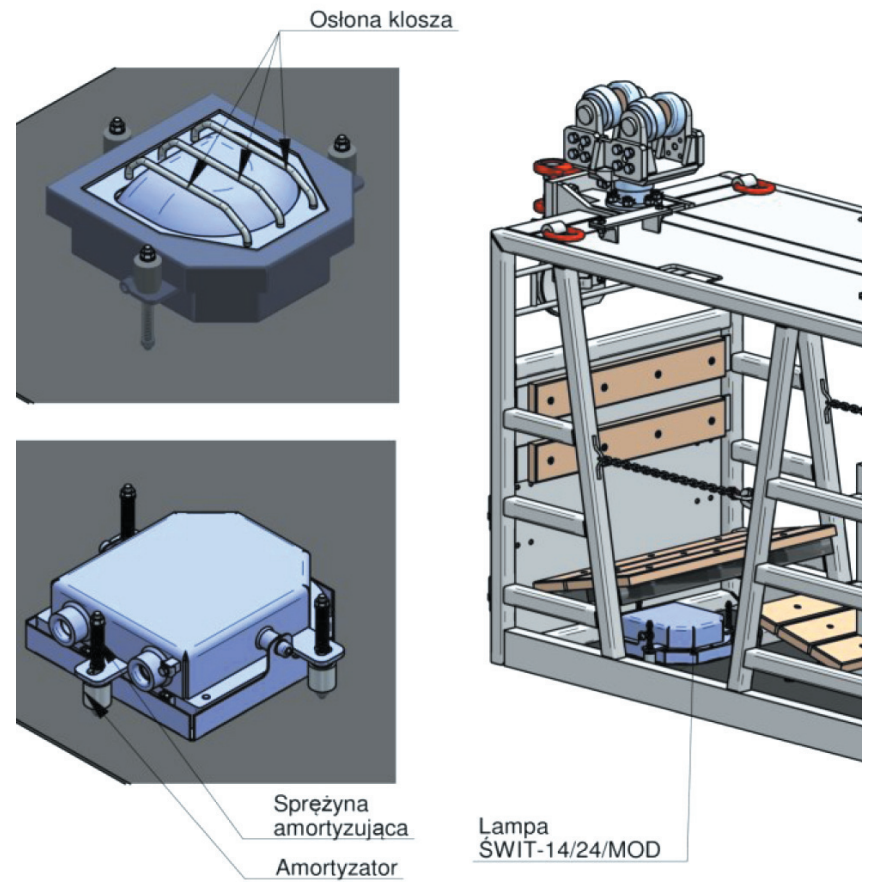

Rys. 3. Przyktadowa zabudowa lamp typu SWIT w kabinie osobowej

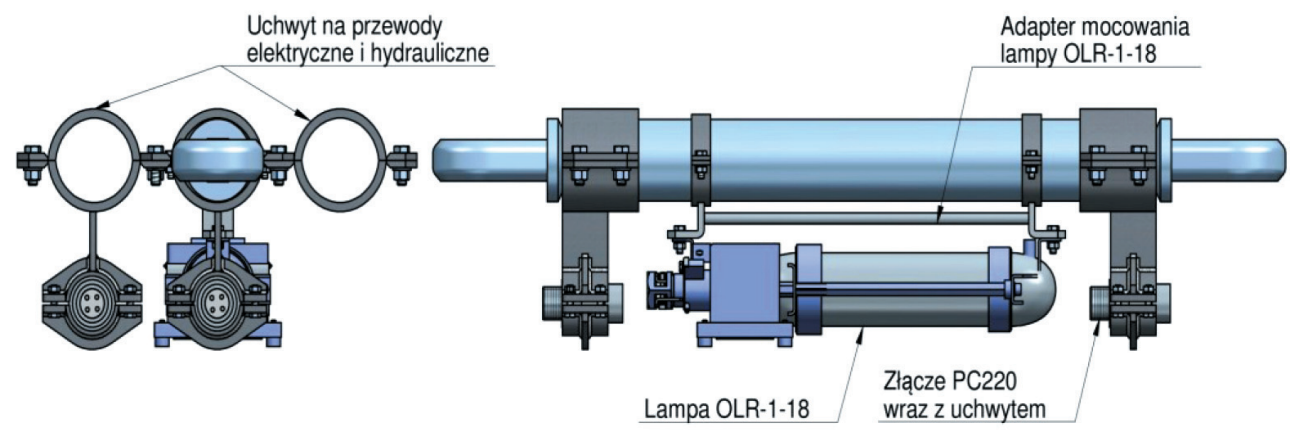

Rys. 4. Przyktadowa zabudowa lampy OLR na zestawie transportowym

Do obliczeń należy przyjmować następujące wartości:

- dwie lampy typu ŚWIT-14/MOD na jedną kabinę osobową $(2 \times 10 \mathrm{~W})$,

- jedna lampa typu OLR-1-18/MOD na jedno cięgło zestawu transportowego $(1 \times 10 \mathrm{~W})$.

Układ zasilania dodatkowego oświetlenia typu UZOD-02 zapewnia realizację wymaganego programu włączania/wyłączania lamp diodowych za pomocą kaset sterowniczych typu KS-01/1/5, tj. załączanie lamp przeznaczonych do oświetlenia stacji osobowych (lampy typu ŚWIT-14/MOD) lub załączania lamp do oświetlenia stacji materiałowych lub też lamp przeznaczonych do załączania jednocześnie lamp do oświetlania stacji osobowych i materiałowych. Przykładowe rozmieszczenie kasety typu KS-01/1/5 w kabinie operatora zostało przedstawione na rysunku 5.

W przypadku obniżenia rezystancji izolacji poniżej $10 \mathrm{k} \Omega$ nastąpi wygenerowanie przez system sterowania ciągnika komunikatu - ostrzeżenia. Urządzenie kontrolujące stan izolacji to standardowe zabezpieczenie instalacji ciagnika zabudowane w zasilaczu typu ZUSD-01.
Po dołączeniu dodatkowych urządzeń (lamp) obwód ten również jest kontrolowany przez to zabezpieczenie.

Kolejnym zabezpieczeniem zabudowanym w układzie zasilania oświetlenia typu UZOD-02 jest zabezpieczenie kontrolujące ciąłość uziemienia na jego odpływach. Każde zakłócenie w instalacji elektrycznej, tj. zwarcie, rozwarcie, zbyt duża rezystancja pętli oraz nieprawidłowe terminowanie obwodu kontroli ciągłości uziemienia czy inne usterki, są dodatkowo monitorowane przez układ sterowania ciągnika i wyświetlane są stosowne komunikaty na wyświetlaczu typu WLM-01 (rys. 7) oraz monitorze stanu pracy maszyny typu MSPM-01 lub MSMP-04 (rys. 6). Terminowanie (zakończenie) obwodu kontroli ciągłości uziemienia odbywa się poprzez zaślepkę ochronną męską typu BM-PC220 lub diodę zabudowaną w lampie.

Zestawy zarówno między sobą, jak i z częścią silnikową są połączone poprzez szybkozłącza serii PC 220. $\mathrm{Na}$ rysunku 8 poniżej przedstawiono przykładową konfigurację ciągnika do transportu ludzi wyposażonego w system złączy serii PC220. 


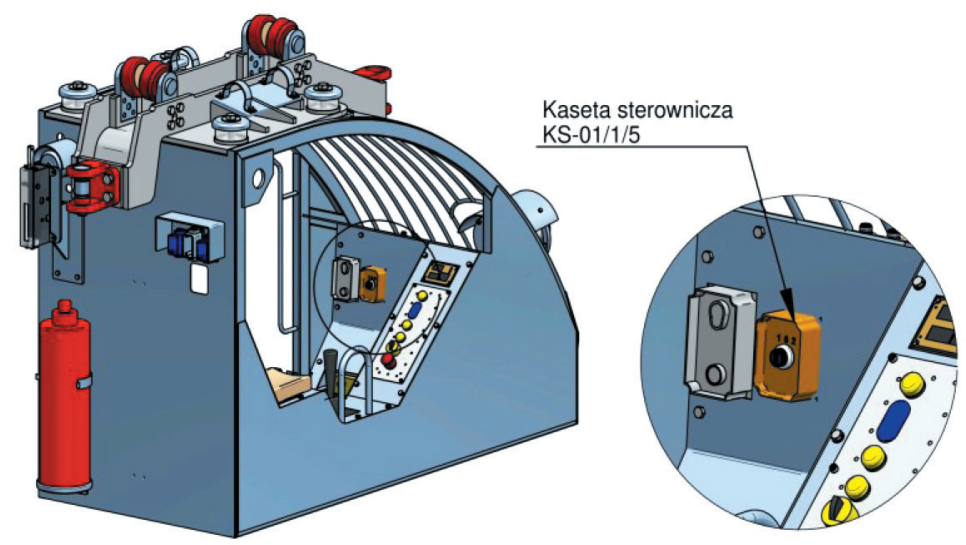

Rys. 5. Umieszczenie kasety typu KS-01/1/5 w kabinie operatora [3]

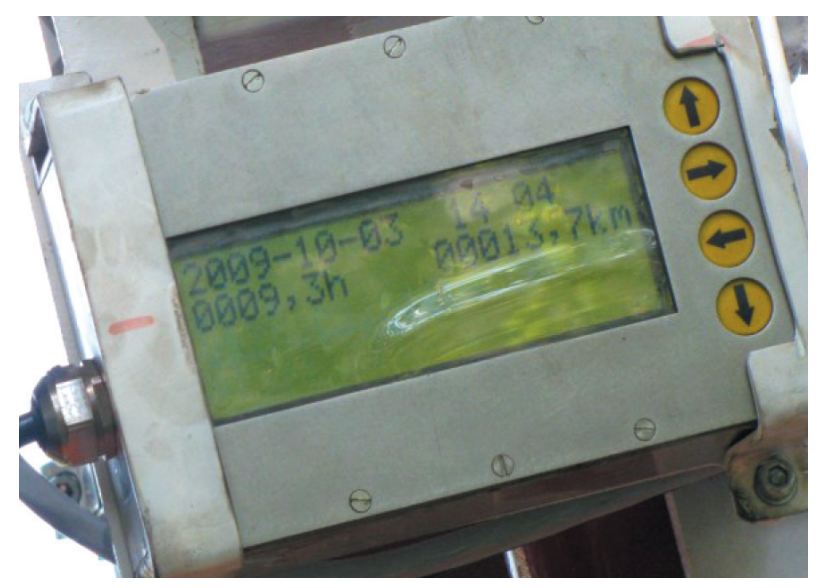

Rys. 6. Monitor stanu pracy maszyny typu MSPM-01

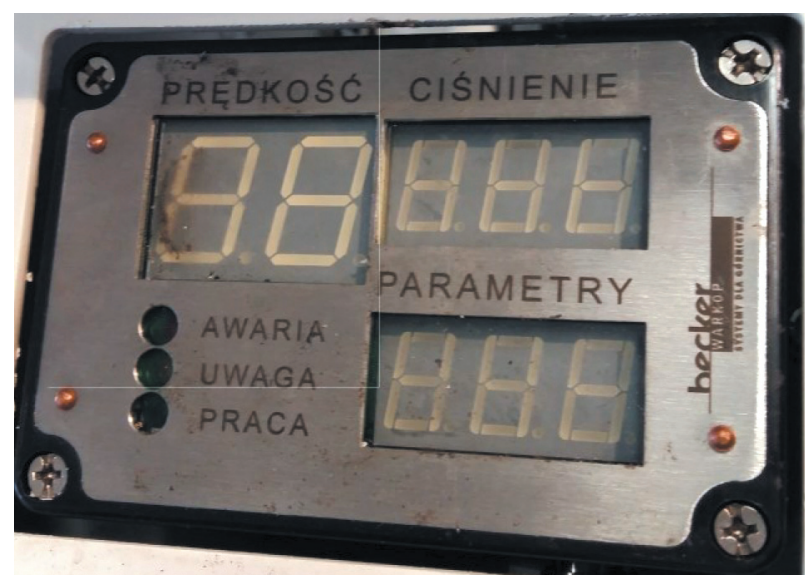

Rys. 7. Wyświetlacz maszynisty WLM-01

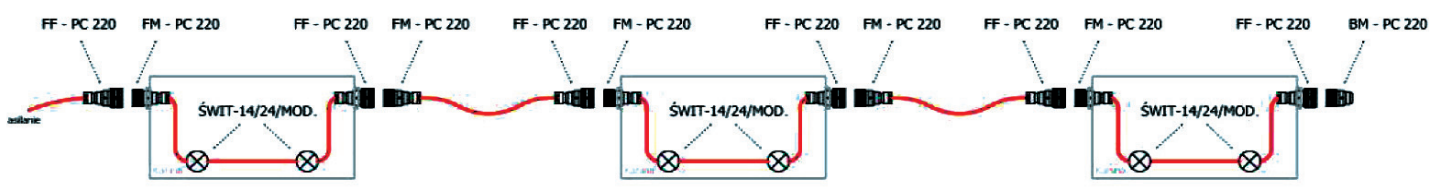

Rys. 8. Przykładowe elektryczne podtaczenie oświetlenia pomiędzy kabinami [2]

Dopuszcza się możliwość wykonywania połączeń między kabinami, zestawami transportowymi za pomocą połączeń przewód - wpust kablowy lampy.

Do lipca 2017 roku przed każdorazowym wprowadzeniem układu mobilnego oświetlenia zastępującego stacjonarne oświetlenie stacji osobowych i materiałowych wymagane było wykonanie pomiarów jego natężenia, współczynnika równomierności i współczynnika zapasu przez wykwalifikowany personel posiadający stosowne uprawnienia.

Podczas wdrażania tego rozwiązania wykonane pomiary przeprowadzone w 2016 roku na stacjach osobowych oraz materiałowych w KWK Krupiński należącej do JSW S.A. przez OPA-ROW Sp. z o.o. (Laboratorium
Badań Środowiskowych) ujęte w sprawozdaniach potwierdziły, że instalacja oświetleniowa zabudowana pod kabinami osobowymi i pod cięgnami zestawów transportowych spełnia wymogi normy PN-G-02600: Oświetlenie podziemnych wyrobisk zaktadów górniczych [5].

Polska norma w punkcie 2.4.1 jednoznacznie definiowała, że w wyrobiskach korytarzowych najmniejsze dopuszczalne średnie natężenie oświetlenia, równomierność oświetlenia oraz współczynnik zapasu powinny odpowiadać wartościom w tabeli 1 .

$\mathrm{Na}$ mocy nowego rozporządzenia Ministra Energii z dnia 23.11.2016 roku w sprawie szczegółowych wymagań dotyczących prowadzenia ruchu podziemnych składów górniczych $\mathrm{w}$ załączniku $4 \mathrm{w}$ punkcie 4.9: 
Tabela 1

Wymagane natężenie oświetlenia według PN-G-02600

\begin{tabular}{|c|c|c|c|c|c|}
\hline \multirow[b]{2}{*}{ Lp. } & \multirow[b]{2}{*}{ Oświetlony obszar } & \multirow[b]{2}{*}{$\begin{array}{c}\text { Oświetlana } \\
\text { powierzchnia }\end{array}$} & \multirow[b]{2}{*}{$\begin{array}{l}\text { Wspól- } \\
\text { czynnik } \\
\text { zapasu }\end{array}$} & \multicolumn{2}{|c|}{ Parametry oświetlenia } \\
\hline & & & & $\begin{array}{c}\text { natężenie } \\
\text { oświet- } \\
\text { lenia } \\
E_{s}[\mathbf{l x}]\end{array}$ & $\begin{array}{c}\text { równo- } \\
\text { mierność } \\
\text { oświetlenia } \\
\delta_{s r}=\frac{E_{\min }}{E_{s r}}\end{array}$ \\
\hline 1 & 2 & 3 & 4 & 5 & 6 \\
\hline 1 & Podszybie & spodek & 1,5 & 30 & 0,4 \\
\hline 2 & Podszybie - wejście do klatki, stanowisko pracy sygnalisty & $\begin{array}{l}\text { spodek, ocios } \\
\mathrm{z} \text { aparaturą } \\
\text { sygnalizacyjną }\end{array}$ & 1,5 & 30 & 0,3 \\
\hline 3 & Stacja osobowa z przewozem szynowym & $\begin{array}{l}\text { spodek od strony } \\
\text { wejścia do wozów }\end{array}$ & 1,5 & 30 & 0,4 \\
\hline 4 & Stacja osobowa z przewozem oponowym & spodek & 1,5 & 20 & 0,4 \\
\hline 5 & $\begin{array}{l}\text { Pomosty do wsiadania na przenośnik i wysiadania } \\
\text { z przenośnika }\end{array}$ & spodek & 1,5 & 20 & 0,3 \\
\hline 6 & $\begin{array}{l}\text { Przekop, chodnik poziomy lub pochyły służące do ruchu } \\
\text { pieszego }\end{array}$ & $\begin{array}{l}\text { spodek, przejście } \\
\text { dla ludzi }\end{array}$ & 1,5 & 5 & 0,2 \\
\hline 7 & $\begin{array}{l}\text { Trasa kolejki i innych środków służących do transportu ludzi } \\
\text { (bez ruchu pieszego) }\end{array}$ & spodek & 1,5 & 2 & 0,2 \\
\hline 8 & $\begin{array}{l}\text { Rozjazdy, rozwidlenia, skrzyżowania, zwężenie, przecięcie } \\
\text { przejścia dla pieszych z trasą przenośnika na głównych } \\
\text { drogach }\end{array}$ & spodek & 1,5 & 10 & 0,3 \\
\hline 9 & Tamy (po obu stronach) na głównych drogach przewozowych & spodek & 1,5 & 10 & 0,3 \\
\hline 10 & Stacja materiałowa, załadowania, przesyp & krawędź wozu, krata & 2,0 & 10 & 0,3 \\
\hline 11 & Granica stacji & spodek & 2,0 & 5 & 0,2 \\
\hline 12 & $\begin{array}{l}\text { Inne stanowiska pracy oraz miejsca zainstalowania } \\
\text { maszyn i urządzeń, środków łączności itp. w chodnikach } \\
\text { i przekopach }\end{array}$ & $\begin{array}{l}\text { spodek lub inne } \\
\text { powierzchnie } \\
\text { robocze }\end{array}$ & 1,5 & 10 & 0,3 \\
\hline
\end{tabular}

Transport linowy oraz zestawami transportowymi z napędem własnym określa się, że:

„4.9.7. Oświetla się:

1) $(\ldots)$;

2) stacje w trakcie załadunku lub rozładunku;

3) stacje osobowe w trakcie wsiadania lub wysiadania osób”.

Podczas przejazdu kolejki z napędem własnym wyrobisko może być dodatkowo oświetlane, co powoduje zwiększenie stopnia bezpieczeństwa.

\section{PODSUMOWANIE}

Powyżej przedstawione, proste, a zarazem innowacyjne rozwiązanie proponowane przez firmę Becker-Warkop wynika z konkretnych potrzeb naszych klientów. Daje ono nie tylko korzyści technologiczne i ekonomiczne w obszarze oświetlenia stacji osobowych i materiałowych, ale również poprawia bezpieczeństwo załogi pracującej na trasie kolejki podwieszanej w momencie szczególnego zagrożenia, czyli podczas przejazdu składu. Jest to jeden z przykładów współpracy firmy Becker-Warkop z klientami, którzy są dla nas inspiracją oraz partnerami.

\section{Literatura}

[1] Aneks nr 6 do Instrukcji (DTR) ciaggnika podwieszanego typu KP-95 - dotyczy mobilnego oświetlenia stacji osobowych i materiałowych.

[2] Instrukcja obsługi lampy typu ŚWIT-14/MOD firmy Elektrometal S.A.

[3] Instrukcja obsługi lampy typu OLR-1-18/MOD firmy Elektrometal S.A.

[4] Karta katalogowa mobilnego oświetlenia firmy Becker-Warkop.

[5] Aneks nr 6 Instrukcji obsługi (DTR) ciagnika podwieszonego typu KP-148 mobilnego świetlenia stacji kolejki KP-148 - dotyczy mobilnego oświetlenia stacji osobowych i materiałowych.

inż. LESZEK $\dot{Z} Y R E K$

dr inż. WOJCIECH ZASADNI

mgr inż. JAN LUBRYKA mgr inż. DAWID JENDYSKA

Becker-Warkop Sp. z o.o.

ul. Przemystowa 11, 44-266 Świerklany

\{l.zyrek, w.zasadni, j.lubryka, d.jendroska\}

@becker-mining.com.pl 